\section{Discussion of "Simulation of Fluid and Inclusions Dynamics during Filtration Operations of Ductile Iron Melts Using Foam Filters"*}

\section{JOHN CAMPBELL}

DOI: $10.1007 / \mathrm{s} 11663-009-9241-3$

(C) The Minerals, Metals \& Materials Society and ASM International 2009

I refer to the article by Davila-Maldonaldo et al. published in the December 2008 issue of Metall. Mater. Trans. $B{ }^{[1]}$ The authors present much interesting and detailed computation of the performance of filters in cleaning ductile irons from particulate inclusions. However, I regret to find myself questioning the relevance of the findings on a number of issues.

(1) The really important inclusions in most metals, including ductile irons, are almost certainly not particles but films. The films entrained by surface turbulence are necessarily always double as a result of the enfolding action of the surface or the collision of droplets, etc. ${ }^{[2]}$ Because the interface between the double films is unbounded, they can act as cracks, which makes them particularly harmful to properties such as elongation and fatigue. Most particulate inclusions are generated intrinsically by reaction and precipitation within the melt (i.e., are not entrained from the outside surface) and so are in perfect atomic contact with the melt. For this reason, they cannot decohere from the matrix nor form cracks or pores. As such, they are usually relatively harmless. ${ }^{[2]}$

(2) The fact that the internal flow of the melt becomes somewhat laminar downstream of the filter is also of little importance. Inclusions, particularly films, still do not have time to detrain even under laminar flow conditions. ${ }^{[3]}$

(3) The really important feature of downstream flow after the filter is the presence or otherwise of surface turbulence. A number of images by the authors indicate that surface turbulence after the filter does occur in a number of their computed results (Figures 15(a), (c), and (d), and Figure 16(b)). These simulations indicate that the melt will be damaged by the entrainment of double films (bifilms) after the filter. This damage might outweigh any benefits

JOHN CAMPBELL, Emeritus Professor Casting Technology, is with the Metallurgy and Materials Department, University of Birmingham, Birmingham B15 2TT, United Kingdom. Contact e-mail: jc@campbelltech.co.uk

*O. DAVILA-MALDONALDO, A. ADAMS, L. OLIVEIRA, B. ALQUIST, and R.D. MORALES: Metall. Mater. Trans. B, 2008, vol. 39B, pp. 818-39.

Article published online May 5, 2009. from filtering a percentage of the incoming inclusions (whether particulate or film type). If the flow channels downstream from the filter are not specifically designed to exclude air, the benefits of filtration can be reversed. ${ }^{[4]}$

(4) Although the authors go to some lengths to define the performance of the filters as filtration devices, Foseco-sponsored work ${ }^{[5]}$ has illustrated that only 10 pct of the cleaning effect of the filter arises as a result of filtration. The remaining 90 pet of the benefit of the cleaning action of the filter derives from potential control of the melt downstream of the filter, simply avoiding entrainment of additional surface oxides. However, this work ${ }^{[5]}$ emphasizes that this benefit cannot be taken for granted; much depends on the design of the downstream flow channels and the opportunity for further entrainment.

(5) Finally, although of reduced significance, the work adopts a vertical down-sprue with a redundant volume at its base, usually known as a "well." Such features increase the damage to the melt by providing the opportunity for additional surface turbulence, thus increasing the load of entrained inclusions that the filter has to remove. A poor down-sprue design followed by a well is the main reason why filters block, overloaded with entrained films. ${ }^{[4]} \mathrm{A}$ blocked filter is very efficient in generating scrap castings.

It is hoped that the authors will consider ways of extending their clearly impressive expertise in application to useful casting problems. For instance, Dispinar ${ }^{[6]}$ finds that, for many Al alloy conditions, the bifilms have a diameter mainly between 0.2 and $2.0 \mathrm{~mm}$. The thickness was not measured but was probably between 0.05 and $5 \mu \mathrm{m}$. Thus, for such inclusions, buoyancy effects are quite negligible. Sirrell ${ }^{[7]}$ found evidence that film inclusions might be shredded in some conditions in filters, resulting in more numerous but smaller defects. The percentage of the filter temporarily blocked by freezing of the melt can be of great importance, particularly for thin-walled castings. ${ }^{[8]}$ There remain plenty of questions for further research.

\section{REFERENCES}

1. O. Davila-Maldonaldo, A. Adams, L. Oliveira, B. Alquist, and R.D. Morales: Metall. Mater. Trans. B, 2008, vol. 39B, pp. 818-39.

2. J. Campbell: Mater. Sci. Technol., 2006, vol. 22, pp. 127-45 and 999-1008.

3. R.W. Monroe and M. Blair: Trans. Am. Found. Soc., 1955, vol. 103, pp. $633-40$.

4. J. Campbell: Castings Practice-The 10 Rules of Castings, Elsevier, New York, NY, 2004.

5. T. Din, R. Kendrick, and J. Campbell: Trans. Am. Found. Soc., 2003, vol. 111.

6. D. Dispinar and J. Campbell: unpublished research, 2009.

7. B. Sirrell and J. Campbell: Trans. Am. Found. Soc., 1997, vol. 105, pp. $645-54$.

8. J.-C. Gebelin and M.R. Jolly: Am. Found. Soc. Trans., 2002, vol. 110 (part 1), pp. 109-19. 